\title{
Prevention of Oil Spills During Excavation Work Using Electromagnetic Sensors
}

\author{
A.S. Rybin ${ }^{1,2}$, Yu.M. Fedorchuk ${ }^{1}$, M.V. Nosova ${ }^{3,4}$, and V.P. Seredina ${ }^{4}$ \\ ${ }^{1}$ National Research Tomsk Polytechnic University, Tomsk, Russia \\ ${ }^{2} \mathrm{OAO}$ Tomskneft of Vostochnaya Neftenaya Companiya, Tomsk, Russia \\ ${ }^{3} \mathrm{OAO}$ Tomsk Oil and Gas Research and Design Institute, Tomsk NIPIneft JSC, Tomsk, Russia \\ ${ }^{4}$ National Research Tomsk State University, Biological Institute, Department of Soil Science and Soil \\ Ecology, Tomsk, Russia
}

\begin{abstract}
This paper presents an analysis of solution to the problems associated with mechanical damage to pipelines. A method of preventing accidental oil spills during excavation using electromagnetic sensors is proposed. The advantages of this method versus alternative options are described herein. A review of existing sensors and methods of their installation on the operating element of excavation equipment is presented. The optimal design solution ensuring accident-free excavation is developed. The economic effect of introducing this technology in the production processes of the oil and gas sector companies is shown.
\end{abstract}

\section{Introduction}

In the context of the active pace of development and operation of oil fields, the natural environment is experiencing substantial pressure, often leading to pollution and deterioration of ecosystems. Oil fields in Western Siberia are the main oil production region in the Russian Federation. Moreover, the soils of these territories have the lowest potential for self-cleaning from technogenic pollutants and a high ability to accumulate pollutants $[1,2]$. Extraction and exploitation of the oil and gas sector, including construction and laying of new pipelines, as well as the recultivation of disturbed soils are accompanied by excavation operations carried out by heavy excavation equipment. Even though the most common reason for accidental oil spills is the loss of pipeline integrity, and according to the failure statistics for $2017-2019,4 \%$ of all incidents on inter-field pipelines occurred due to mechanical damage to the pipeline during excavation work. Thus, the studies that can computerize key production processes and enhance compliance with the high environmental and industrial safety standards at companies of the oil and gas sector are becoming more relevant.

Scientific developments of foreign and domestic researchers conclusively prove that improvement of any method, development of any measures aimed to computerize production processes shall begin with the clarification, identification, and assessment of the actual status, i.e., with the process of diagnostics and comparison of alternative methods they developed and ways to improve those [3-5]. Considering that innovation and automation of production processes [6,7] are the most important factors of competitiveness of oil and gas players in present-day market conditions, determination of the directions of 
their development, as well as the development of sound organizational changes allows to create a stable foundation for further development and achievement of the main strategic goals of companies. However, it should be noted that the finalization of the innovative solutions portfolio is directly associated with the economic assessment of the implementation of this solution into production processes. Therefore, the purpose of this study is an economic analysis and the implementation of prevention of oil spills during excavations by equipping operating members of field support vehicles with a detection range sensor to the pipeline.

To satisfy this goal, the following tasks were set:

- Consideration of the relevance of the use of 2D and 3D leveling systems, analysis of their advantages and disadvantages, as well as the possibility and degree of their applicability during excavation;

- Analysis of the ways to solve the problem of mechanical damage to pipeline during excavation, an overview of various types of existing sensors and methods of their installation on the operating members of field support vehicles;

- Proposal of the best design option how to install sensors on the operating members of an excavator.

\section{Material and methods}

The article is based on the statistical data related to pipeline ruptures in the area of Alexandrovskoye and Kargasok localities of the Tomsk Region and Nizhnevartovsk area of the Khanty - Mansiysk Autonomous Okrug - Ugra. The object of the study is the method of excavation using electromagnetic sensors. A review of existing approaches was carried out taking into account foreign experience in scientific and technical solutions ensuring the safe conduct of operations and generally accepted occupational safety requirements. Assessment of the economic effect of the proposed design was obtained by evaluating investment projects noising the method of discounted cash flows (calculation of NPV, IRR, PP, DPP).

\section{Results}

$2 \mathrm{D}$ and 3D leveling systems may be singled out [8-10] among the existing systems of automation equipment for excavation.

The main functions of such systems include:

- Control of the depth and deviation during the excavation of the pit: the operator puts the ladle on the reference level (elevation) and enters the calculated elevation into the program, indicating the tangent angle of the slope. The system analyzes these parameters and displays actual and design values. Once the data is received, the operator performs work based on the displayed readings, tracks the high-altitude position of the ladle relative to the benchmark in real-time mode. When the set level is reached, an audio signal sounds and a green diode lights up on the panel;

- Excavation of a cutout or a backfill of a complex profile embankment;

- Setting a "dead zone", when reached, the hydraulic control is blocked - used to protect the excavator (the possibility of digging is excluded), the protection of utilities from the ladle, which was not properly passedbelow the digging depth, etc.

Simulation analysis showed that the initial position of the ladle for a 2D control system can be fixed at some point with a known mark or on a laser plane. In 3D systems, the excavator is determined in absolute coordinates in the digital model of the required surface (Figure 1). 
The use of the described 2D systems for safe excavation seems inexpedient as long as the complexity of synchronization of pipeline location, parameters of the pit, and excavator placementdoes not allow us to complete the task.

The use of 3D systems for the safe conduct of excavation seems to be inexpedient due to their high cost (6 million rubles per system), as well as the need to engage and pre-train engineering staff to develop a digital model.

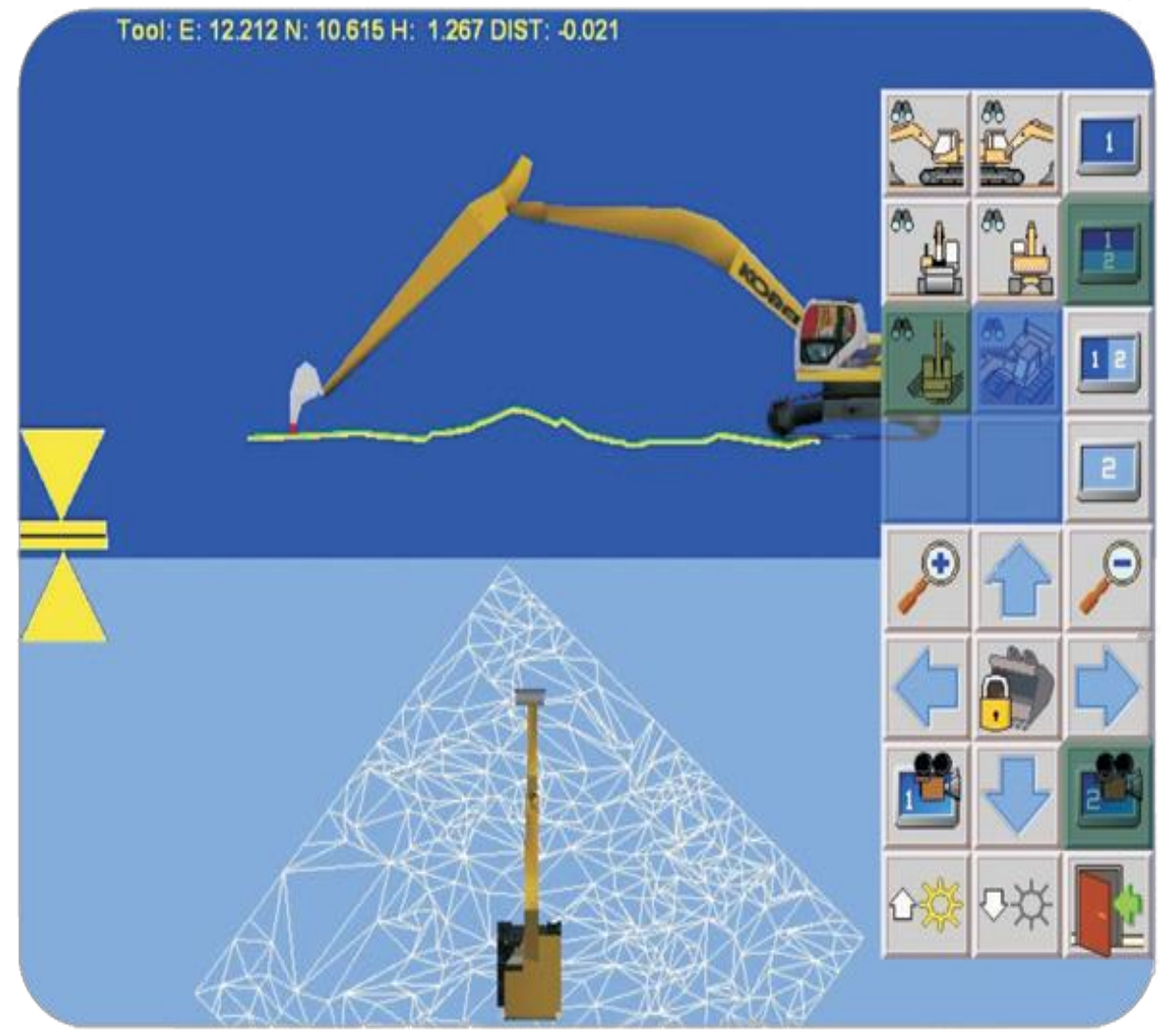

Fig.1. Digital model of the 3D leveling system.

The highest-quality technical model is the development of the ladle approach prevention package to underground utilities by EZiDIG (Italy). The warning is in real-time mode, the sensitive control of the fixture is mounted on the excavator handle. The fixture is designed to search for signal and power cables in the basic configuration. When the signal generator is connected, you may control the position of other utilities that do not independently generate the electromagnetic signal. EZiDIG is not available on the Russian market and has no domestically produced equivalents. This complicates the implementation of this equipment, increases the risks and the cost of its maintenance. Thus, there are no readymade quality solutions on the domestic marketto mitigate pipeline damage during excavation.

Another approach to problem-solving may be the use of sensors capable to detect the pipeline. The sensors due to optical earth opacity are not applicable in excavation.

It seems promising to apply electromagnetic sensors used in pipeline finders and geo radars. One of the main advantages of magnetic displacement sensors is that a magnetic field may penetrate through all non-magnetic materials without loss of the accuracy of sensing the distance to the object. This means that no matter what kind of obstacle is there 
between the sensor and the object, be it stainless steel, aluminum, brass, copper, plastic, stone, or wood, the distance between them will be detected almost immediately. Another advantage of magnetic sensors is that they can operate in harsh environmental conditions and are corrosion resistant, as both detectors and objects, if necessary, can be coated with inert materials that have no effect on magnetic fields.

The use of electromagnetic sensors is complicated by the proximity of massive metal parts of the excavator itself, as well as their mobility. An obvious difficulty is how to select sensor installation locations. To ensure proper operation, there should be no metal objects in the vicinity of the unshielded eddy current sensor. A similar disadvantage can be remedied by shielding the sensor. Two eddy current sensor configurations are shown: with and without shielding (Figure 2).

The shielded sensor consists of a metal sheath around the ferrite core and coilsfocusing the electromagnetic field on the front side of the sensor. This allows them to be integrated into metal structures without changing the measuring range. The unshielded sensor is sensitive to movement not only from the front end but also from the sides. The required passive search frequency is $50-100 \mathrm{~Hz}$. The temperature ranges from $-20^{\circ} \mathrm{C}$ to $+50^{\circ} \mathrm{C}$ which is acceptable for operation in all weather conditions. After installing the sensor, the depth of the utilities is displayed on the screen, which is important when assessing the volume of earthworks. In addition to graphic and digital information, the device provides sound notification, the type and volume of which depend on the position of the communication and the signal level.

Thus, the technical result of the implementation of this method is the improvement of the accuracy of determining a critical distance between the excavator ladle and the pipeline wall surface.

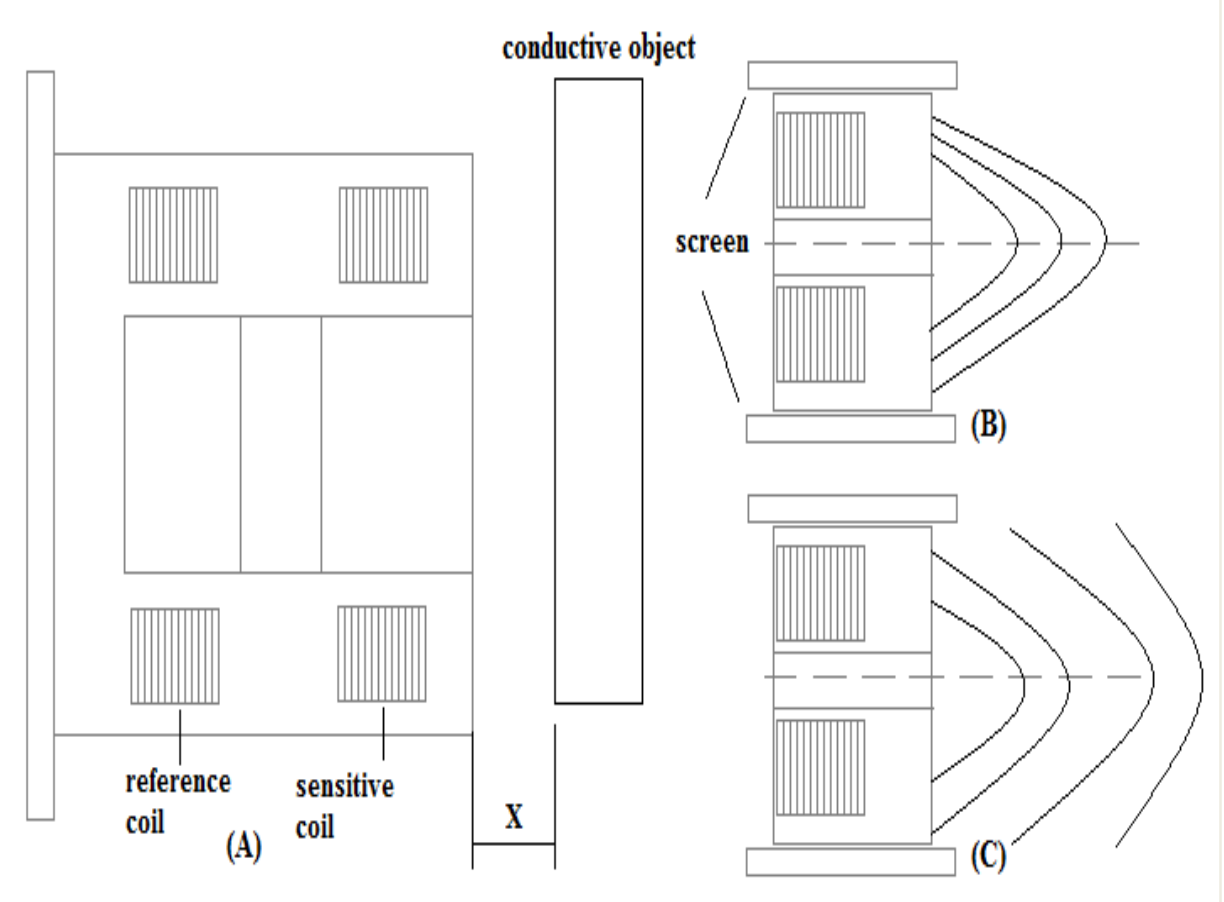

Fig.2. A - Electromagnetic proximity sensor, B - shielded sensor, C - unshielded sensor. 
A common practice for the above-described systems is the installation of equipment on the handle of the excavator. This position of the sensors prevents from considering the position of the ladle during movement. The sensor's installation location, ensuring the safety of the pipeline, is fixed on the ladle teeth (Figure 3).

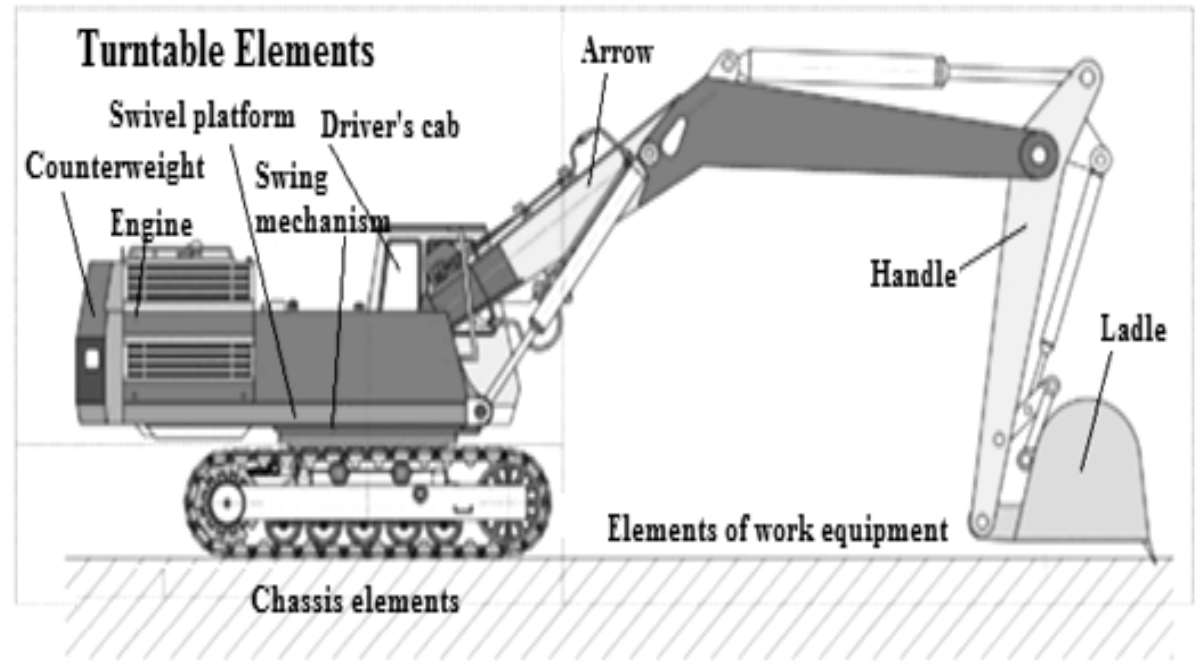

Fig.3. The layout of the elements of the excavator.

Installation of even small sensors on the teeth is a difficult task, as these locations are subject to pressure and wear during the operation of the excavator. Therefore, installation of the sensor on the skid fixed to the handle and reproducing the ladle perimeter can be a fairly simple option. Considering the prevalence of the use of magnetic sensors and the existence of similar tools, the operation principle of which is similar to the designed one, the development of a prototype of the required electronic equipment is not associated with high risks and costs.

Economic calculation of the costs associated with the localization and elimination of oil spills is based on the real case of oil and oil products leakage as a result of loss of integrity of oil field pipelines k.2X-vr.2K "Oil Field N" (Table 1).

The costs of remediation of contaminated areas are assessed based on the costs of special equipment: sectional reservoir RS-4, gas detector GSM-03-01-4 / 2 / A-1-1-3, sorbent spray PAS (including depreciation) - 2809.7 rudders. The cost of materials and components include: the Newsorb sorbent, the Spill-Sorb absorbent, the PDU-3 portable breathing device, 85,327.5 rubles; the cost of attracting equipment from contractors, $261,336.79$ rubles. Also, in the calculation of the costs, works to restore the fertile layer of the land plot (collecting oily liquid, adding lime, using destructive microbes and mineral fertilizers, performing sitrsurvey, milling, seeding grasses, chemical analysis of soils) are taken into account -217414.0 rubles.

Table 1.The economic effect of the project.

\begin{tabular}{llll}
\hline Parameter & Unit of measurement & ParameterDefinition & Totalindicator \\
\hline NPV & millionrubles & Netpresentvalue & $1,950,030$ \\
IRR & $\%$ & Internalrateofreturn & 100 \\
PP & year & Paybackperiodsimple & $<1$ \\
DPP & year & Discountpaybackperiod & $<1$ \\
\hline
\end{tabular}


Taking into account the cost of geolocators and pipeline finders, it can be assumed that the cost of equipment for one excavator will not exceed 468,000 rubles (without VAT). Thus, the economic effect of the project with the specified macro parameters (annual discount rate of $20 \%$, estimated period 10 years) will pay back the preliminary expenses for the adaption of the technology in less than 1 year, and it will cost about $601,835.5$ rubles to rectify the consequences of only one incident associated with the damage of pipeline surface by excavator equipment (without taking into account expenses for reclamation).

\section{Conclusion}

Incidents during excavation due to the damage to the pipeline by the excavator ladle lead not only to economic losses but also cause a great harm to the environment.

Among the existing solutions for excavation equipment, we can highlight the 2D and $3 \mathrm{D}$ leveling systems, as well as the EziDig excavator system. The use of 2D systems for the safe conduct of excavation seems to be inexpedient, due to the complexity of synchronization of the pipeline location, parameters of the pit, and location of the excavator. The use of 3D systems for the safe conduct of excavation is not an ultimate solution due to their high cost ( 6 million rubles per unit), as well as the need to engage pretrained engineering staff to develop a digital model. Adaptation of the sensors developed by EZiDIG into the production processes does not seem feasible, as such models and their analogs are not available on the Russian market. These factors complicate the adaption of this equipment, increase the risks and costs associated with adaption and maintenance.

The most promising way is the development of a pipeline detection tool based on the electromagnetic sensors used in the pipeline finders and geo radars. The implementation of such a tool is complicated by the proximity of the massy metal parts of the excavator, as well as their mobility. Installation of sensors on a special skid fixed to the handle and reproducing the ladle perimeter may become a fairly simple option. Adaption of such sensors is a current concern and a very economically viable solution that does not require significant capital investments and labor costs, and will also make it possible to eliminate the human factor and fully computerize the earthwork process.

\section{References}

1. Seredina, V. \& Sadykov, M. 2011. Soils of oil fields in the middle taiga of Western Siberia and a predictive assessment of the danger of pollution by organic pollutants. Siberian Journal of Ecology 5(18):617-623.

2. Seredina, V. \&Kolesnikova, E. \&Kondykov, V. \&Nepotrebnyy, A. \&Ognev, S. 2017. Features ofthe effect of oil pollution on soils of the middle taiga of Western Siberia. Oil industry 5: 9-20.

3. Yashin, S. \&Koshelev, E. \&Makarov, S.2012. Analysis of the effectiveness of innovative activity. SPb: BHV.

4. Blinkov, I. \& Blinkov, O. 2019. Evaluation of the effect of innovations adaption as a factor of thecompetitive immunity of an industrial enterprise. Equipment and technologies for the oil and gas complex 4: 48-51.

5. Lisanov, M. 2010. The risk analysis of trunk oil pipelines when substantiating the design solutions thatcompensate for the deviations from the existing safety requirements. Industrial safety 3: 58-66.

6. M. Lisanov, E. Shanina, A. Savina, A. Taran, S. Sumskaya, I. Naumovich, A. Lesnyak, The risk analysis of trunk oil pipelines when substantiating the design solutions that 
compensatefor the deviations from the existing safety requirements. Industrial safety, $\mathbf{3}$ (2010).

7. I. Tararychkin, S. Blinov, Simulation modeling of the damage process of the network pipelinestructures. Mir Transporta /The World of Transport 15(2): 6-19. (2017).

8. G. Ustavich, Geodetic surveys during construction and operation of large-scale power supply facilities. (Moscow: Nedra, 1983).

9. U. Saponenko, Single ladle excavator operator. (Moscow: Academiya, 2008).

10. I. Bukreyev, 3D leveling systems as applicable to excavators. Roads and People, 11: 14-16. (2012). 